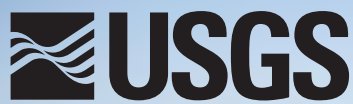

\title{
Cooperative Fish and Wildlife
} Research Units Program2018 Year in Review

U.S. Department of the Interior U.S. Geological Survey 
Dear friends,

I invite you to take a look at the U.S. Geological Survey Circular 1452, “Cooperative Fish and Wildlife Research Units Program-2018 Year in Review," now available at https://doi.org/10.3133/cir1452. In this report, you will find details about the activities of the Cooperative Fish and Wildlife Research Units (CRU) program in 2018 relating to fish and wildlife science, students, staffing, vacancies, research funding, outreach and training, science themes, background on the CRU program, accolades, and professional services. You will see snapshots of CRU projects with information on how results have been or are being applied by cooperators. This is the essence of what we do: science that matters.

Throughout the year, keep up with our research projects at https://www.coopunits.org.

\section{Regards,} John F. Organ, Ph.D., CWB® Scientist Emeritus, Cooperative Fish and Wildlife Research Units

Front photograph credit: Hayley Glassic (Ph.D. student with Dr. Christopher Guy at the Montana Cooperative Fishery Research Unit) releases a tagged paddlefish in the Missouri River above Fort Peck Reservoir.

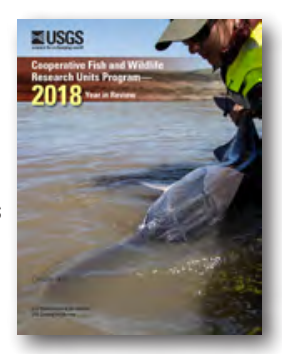

\section{@USGSCoopUnits}

@CRU1935

@USGSCoopUnits

@USGSCoopUnits
ISSN 2332-3531 (print)

ISSN 2332-354X (online)

https://doi.org/10.3133/gip187
Place

Stamp

Here 